\title{
PERSPECTIVE
}

\section{The neuroscience of suicidal behaviors: what can we expect from endophenotype strategies?}

\author{
P Courtet ${ }^{1}$, II Gottesman ${ }^{2,3}$, F Jollant ${ }^{4}$ and TD Gould ${ }^{5}$
}

Vulnerability to suicidal behavior (SB) is likely mediated by an underlying genetic predisposition interacting with environmental and probable epigenetic factors throughout the lifespan to modify the function of neuronal circuits, thus rendering an individual more likely to engage in a suicidal act. Improving our understanding of the neuroscience underlying SBs, both attempts and completions, at all developmental stages is crucial for more effective preventive treatments and for better identification of vulnerable individuals. Recent studies have characterized SB using an endophenotype strategy, which aims to identify quantitative measures that reflect genetically influenced stable changes in brain function. In addition to aiding in the functional characterization of susceptibility genes, endophenotypic research strategies may have a wider impact in determining vulnerability to SB, as well as the translation of human findings to animal models, and vice versa. Endophenotypes associated with vulnerability to SB include impulsive/aggressive personality traits and disadvantageous decision making. Deficits in realistic risk evaluation represent key processes in vulnerability to SB. Serotonin dysfunction, indicated by neuroendocrine responses and neuroimaging, is also strongly implicated as a potential endophenotype and is linked with impulsive aggression and disadvantageous decision making. Specific endophenotypes may represent heritable markers for the identification of vulnerable patients and may be relevant targets for successful suicide prevention and treatments.

Translational Psychiatry (2011) 1, e7; doi:10.1038/tp.2011.6; published online 10 May 2011

\section{Introduction}

The increased use of pharmacological treatments for psychiatric diseases over the previous decade has had limited effect on decreasing the overall rates of attempted and completed suicides. ${ }^{1}$ There is a pressing public health need to revisit existing strategies and notably to promote preventive action specifically directed toward those most at risk for suicide. To achieve this goal, suicide prevention strategies require the identification of at risk individuals, and the development of specific and targeted interventions for those individuals, independently of any coexisting psychiatric diagnoses.

The term suicidal behavior (SB) refers to a heterogeneous outcome of suicide attempts and suicide completions. ${ }^{2}$ Support for SB as an entity is multifold. Although it is well known that the nature of a suicidal act (suicide attempt or completed suicide) may be influenced by gender, age, availability of a lethal mean and specific suicidal dimensions, such as suicidal intent and medical lethality, these behaviors seem to have more in common and are often distinguished from another component of the suicidal process, namely, suicidal ideation. The clinical profiles of suicide attempters and completers overlap. ${ }^{3}$ In addition, previous suicide attempt is an important predictor of future suicide. ${ }^{4}$ Epidemiological genetics studies suggest that suicide attempts and completed suicides may share a common genetic basis. ${ }^{5}$ Furthermore, there is limited support that suicidal thoughts run in families, or that they are predictive of suicide attempts or completions within families. ${ }^{6}$ Finally, suicide attempts and suicide completions share many neurobiological correlates. ${ }^{7,8}$

An historic turning point in suicidology resulted from the demonstration that psychobiological abnormalities are associated with vulnerability to $\mathrm{SB}$, independently of co-occurring psychiatric disorders. ${ }^{7}$ On the basis of cumulative results, a general model has been proposed postulating that vulnerability to SB is mediated in part by an important underlying genetic predisposition interacting with environmental and probable epigenetic factors throughout the lifespan; this combination of risk factors then modifies the function of neuronal circuits, thus rendering an individual more likely to engage in a suicidal act. ${ }^{9,10} \mathrm{~A}$ number of identified biological impairments are coincident with personality traits related to impulsivity, aggression, neuroticism or hopelessness, which confer vulnerability to SB that is expressed in the context of aversive life events. ${ }^{11-13}$

\footnotetext{
${ }^{1}$ Department of Emergency Psychiatry, CHRU Montpellier, Inserm U1061, University of Montpellier I, Montpellier, France; ${ }^{2}$ Department of Psychiatry, University of Minnesota Medical School, Minneapolis, MN, USA; ${ }^{3}$ Department Psychology, University of Minnesota, Minneapolis, MN, USA; ${ }^{4}$ Douglas Mental Health University Institute, McGill Group for Suicide Studies, McGill University, Montreal, Quebec, Canada and ${ }^{5}$ Departments of Psychiatry, and Pharmacology and Experimental Therapeutics, University of Maryland School of Medicine, Baltimore, MD, USA

Correspondence: Dr TD Gould, Department of Psychiatry, and Pharmacology and Experimental Therapeutics, University of Maryland School of Medicine, Room 934D MSTF, 685 West Baltimore Street, Baltimore, MD 21201, USA.
}

E-mail: gouldlab@me.com

Keywords: animal models; biomarker; decision making; emotions; orbitofrontal cortex; suicide

Received 22 March 2011; accepted 23 March 2011 
These ideas about SB further stimulate research aimed at identifying the etiological factors and their effects on the processes of brain and psychological development, leading to a better understanding of the pathophysiology and phenomenology of SB. Hopefully this will help to create tools for the early detection of $S B$ and new strategies for targeted prevention. With this aim in mind, the search for endophenotypes represents a valuable emerging strategy for the identification of susceptibility genes and should improve insight into relevant biological systems, sub-classification of patients and treatment approaches. ${ }^{14,15}$

\section{The endophenotypic approach}

Endophenotypes were originally described as internal phenotypes that mediate on the path between genes and the diseases genes moderate. ${ }^{16,17}$ Their fundamental relevance was related to, but not necessarily dependent on, the assumption that endophenotypes represent less complex clues to genetic underpinnings than the disease syndrome itself, promoting the view that psychiatric diagnoses can be optimally deconstructed, resulting in more straightforward and successful genetic analysis. ${ }^{17,18}$

The most commonly accepted criteria for a genetically influenced endophenotype include trait identification in an objective and quantitative manner in patients before onset of the disorder and/or periods of remission. State independence or longitudinal stability should be further established in longitudinal studies with repeated measures. Finally, epidemiological studies should be examined to determine whether the endophenotype co-segregates with SB in family members and is also found in non-affected family members at a higher rate than that in the general population. The endophenotype should therefore run in families and be associated with an increased risk of clinical illness. Such criteria are useful to distinguish endophenotypes from biological markers; the latter meet few of the above mentioned criteria and for this reason would likely not direct clinical research in psychiatry toward genetically meaningful conclusions. Our armamentarium used to assess endophenotypes includes, though is not limited to, neurophysiological, biochemical, endocrinological, neuroanatomical/imaging, cognitive and neuropsychological measures. $^{17}$

As a heuristic model, one can consider a cascade from the studied phenotypic syndrome to the genes, with different levels of analysis: syndrome-mediating dimension/trait; self-report measure/clinical interview; laboratory behavioral task performance; cognitive task performance; psychophysiological task performance; functional, structural and neurochemical imaging; postmortem neurochemistry, cell structure, mRNA expression; genotype. ${ }^{19}$ These complementary approaches, when used in the identification of endophenotypes for SB may provide convergent validity for the most promising endophenotypes, ${ }^{17,19-21}$ while noting that predicting rare events such as SB (especially completed suicides) adds to the difficulties of such research. ${ }^{22,23}$

It is known from twin studies that genetic susceptibility factors, independent of an additional psychiatric diagnosis, modify the risk of SB. ${ }^{6,24,25}$ Therefore, it is probable that genetically delineated endophenotypes exist that are asso- ciated with such behaviors. ${ }^{14,26}$ Although there are many potential endophenotypes that are associated with $\mathrm{SB},{ }^{27}$ we selectively provide a brief review of some associations (Figure 1). As reviewed previously, additional putative endophenotypes may be considered for further researches. ${ }^{14}$ Specific psychiatric disorder subtypes (for example, early onset major depressive disorder) and personality dimensions or disorders (for example, borderline personality disorder) have also been linked to SB. ${ }^{14}$ Few of the reported alterations fulfill the complete definition of an ideal endophenotype. As such, a majority of the studies reported below should be seen as promising, but not yet definitive, areas of research.

Impulsivity-aggression. The most reproduced associations between suicide and personality measures are with indicators of aggression and impulsivity, which meet most, if not all, stringent endophenotype criteria (as detailed in Mann et al. ${ }^{14}$ and Kovacsics et al. ${ }^{28}$ ). These endophenotypes can be readily quantified using self-report data from suicide attempters and their relatives, or by psychological autopsy methods. $^{12,14}$ Impulsivity and aggression are related and many studies have also examined 'impulsive aggression' in populations with SBs. Specifically, a number of studies have found that both impulsivity and aggression meet criteria for endophenotypes such as being heritable, associated with suicide, state independent and co-segregating with SB in families. ${ }^{29-33}$ The data suggesting that aggression and impulsivity are valid candidate endophenotypes of SB include case-control, retrospective (psychological autopsy), prospective longitudinal and family studies. ${ }^{32,34}$ Laboratory assessments of impulsive aggression may be more reliable than clinical assessments, promoting the use of neuropsychological tools. ${ }^{14}$ It is a promising approach to move from personality dimensions defined at the complex level of the psychopathology derived from self or clinician reports, to more subtle traits with presumably more precisely definable neurobiological underpinnings. Neuropsychological tools may help to avoid the pitfalls related to the use of personality dimensions, yielding 'stronger' endophenotypes. ${ }^{35}$ Although there is overwhelming evidence to support the role of impulsive-aggressive behaviors in suicide, not all suicides are mediated by impulsive-aggressive behaviors. Thus, impulsive aggression probably characterizes only a subgroup of patients with SB, and there remain a number of other vulnerability factors.

Disadvantageous decision making. Decision making, as quantitatively defined in the lowa gambling $\operatorname{task}^{36}$ that compares choosing between disadvantageous choices for which a lot of money is won but even more is lost (resulting in a net loss) and advantageous choices where less is won but even less is lost (resulting in a net gain), shows associations with SB. A significantly higher tendency toward disadvantageous choices was found in patients with a history of SB compared with patients without any such history and to healthy controls. ${ }^{37}$ Patients were euthymic at the time of assessment, suggesting a trait, rather than state, finding. This impairment was not related to comorbid axis-I disorders. ${ }^{37}$ Similar alterations in suicide attempters were 


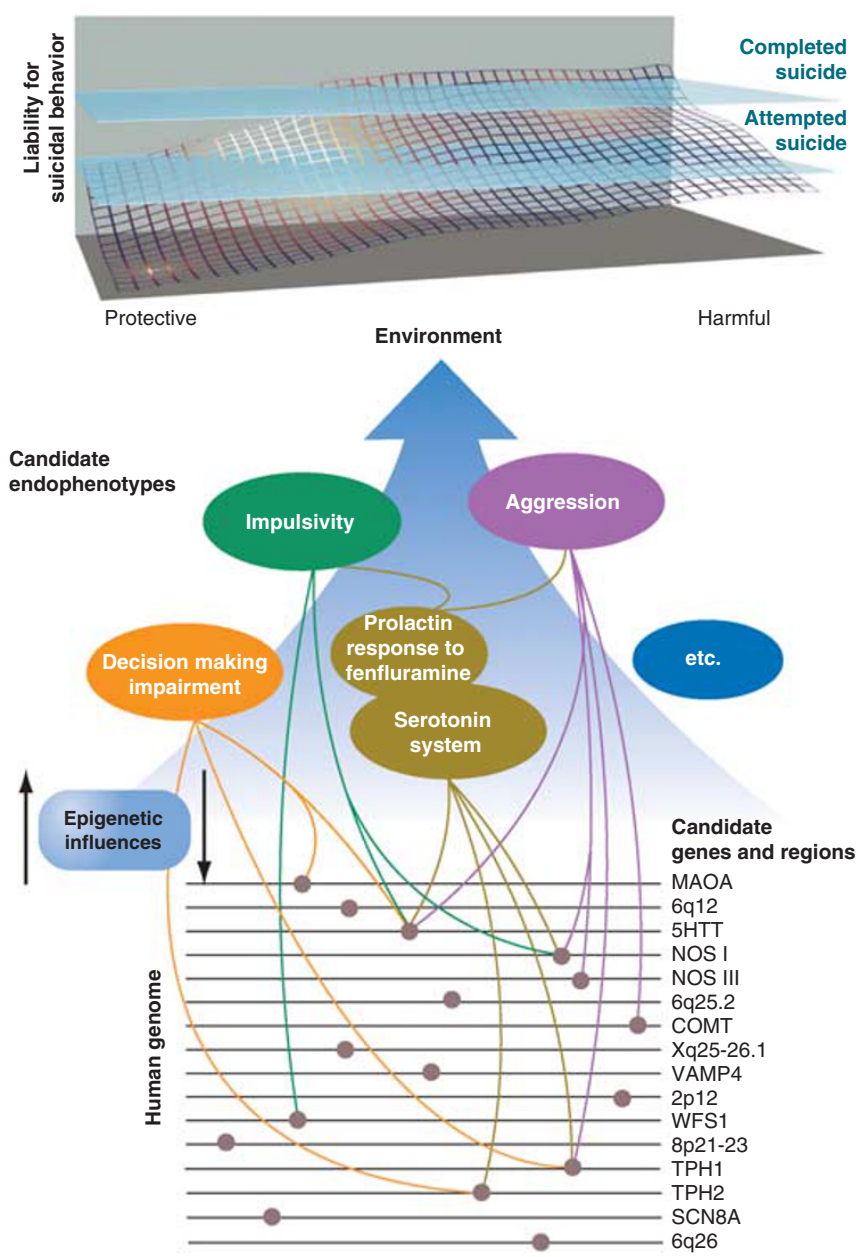

Figure 1 Candidate gene regions, genes and endophenotypes implicated in suicide research. The upper portion of the figure indicates the dynamic interplay among genetic, epigenetic and environmental factors that produce cumulative liability to suicidal behaviors. Although attempted suicide does not always predate a completed suicide as suggested on the reaction surface, it is a significant risk factor. ${ }^{4}$ None of the sections of this figure can be definitive; many more gene loci, genes, candidate endophenotypes and links among the three remain to be discovered. Environment, protective and harmful, includes a substantial number of environmental events (for example, drug exposure) unmentioned here because of our focus on genetic and neurobiological correlates. Similarly, there are many gene loci, genes and candidate endophenotypes that were not included because of the conceptual limitations of this Figure. Modified from Kovacsics et al. ${ }^{28}$ See the following reviews for additional discussion: refs $7,12,14,25,28$, 96-98. (C) II Gottesman and TD Gould and used with permission.

recently reported in patients suffering from major depressive disorder, ${ }^{38}$ bipolar disorder ${ }^{39,40}$ and also in self-harming adolescents. ${ }^{41}$ Most recently, disadvantageous decision making was found deficient in elderly suicide attempters versus elderly suicide ideators, non-suicidal depressed and non-depressed subjects in a reward/punishment-based task. $^{42}$ Although decision making has not been formally studied in relatives of suicide attempters/completers, one study reported decision-making alterations in unaffected relatives of alcoholics suggesting that this cognitive dysfunction may be heritable. ${ }^{43}$ Jollant et al. ${ }^{44}$ reported that genetic polymorphisms previously associated with SB including the serotonin transporter promoter variant (5HTTLPR), tryptophan hydroxylase 1, and monoamine oxidase A modulated the learning process necessary in the lowa gambling task for making advantageous choices in suicide attempters. The 5HTTLPR association has also been confirmed in an obsessive-compulsive disorder population ${ }^{45}$ and in healthy individuals. ${ }^{46}$
Altered skin conductance. An association has been found between a stimulus-elicited electrodermal response (hyporeactivity), as measured by skin conductivity, and SB in several studies (see Thorell ${ }^{47}$ for meta-analysis). Moreover, electrodermal activity during decision making seems to implicate key brain regions associated with SB (see below), such as the ventral and medial prefrontal cortices. ${ }^{48}$ Electrodermal reactivity is under genetic influence, with a heritability of $\sim 50 \%$ in healthy twins, ${ }^{49}$ and is state independent. ${ }^{50}$ In addition, an electrodermal response has been correlated with decision making in the lowa gambling task in healthy subjects. ${ }^{51}$ Therefore, electrophysiological hyporesponsivity may be an endophenotype partially linked with poor decision-making abilities.

Neuroimaging. At the neuroanatomical level, postmortem studies have implicated involvement of the prefrontal cortex, particularly the most ventral regions including the orbitofrontal cortex. ${ }^{52}$ These regions have been reported to be different from controls in structural neuroimaging studies 
of different populations of suicide attempters. ${ }^{53-55}$ Pharmacological neuroimaging studies have highlighted the particular importance of the prefrontal cortex. Two studies showed reduced prefrontal $5 \mathrm{HT}_{2 \mathrm{~A}}$ receptor binding in $\mathrm{SB}^{54,56}$ Cannon et al. $^{57}$ found increased binding of the serotonin transporter in the anterior cingulate gyrus of bipolar patients with a history of suicide attempts compared with those without a past history of attempts. Finally, Leyton et $a .^{58}$ reported reduced levels of $\alpha-[11 \mathrm{C}]$ methyl-Ltryptophan in the ventral and lateral prefrontal cortex of high-lethality suicide attempters compared with healthy controls. These findings support the idea that altered serotonergic modulation may modulate prefrontal cortex dysfunctions, though their genetic basis is unclear.

Using functional neuroimaging, previously depressed male suicide attempters, in comparison with previously depressed male patients with no history of suicide attempts, were found to have higher activation of the right orbitofrontal cortex in response to viewing angry versus neutral faces. ${ }^{59}$ This activation was not found when happy faces were presented. Of note, all patients were euthymic at the time of scanning. It was hypothesized that patients with a vulnerability to SB may have a particular sensitivity to rejection and disapproval (expressed by angry faces), modified by orbitofrontal cortex dysfunction. Other findings suggest lower activation of the left lateral orbitofrontal cortex in suicide attempters versus nonattempters during risky versus safe choices as measured in the lowa gambling task. ${ }^{60}$ Decision-making impairment in suicide attempters is therefore associated with the decreased ability of these patients to correctly learn to recognize longterm risk in uncertain situations.

Positron emission tomography imaging has shown that there is reduced activation of the medial prefrontal cortex in high versus low lethality suicide attempters, ${ }^{61}$ a difference accentuated by fenfluramine, a serotonergic agonist. This is consistent with the reproduced finding that the prolactin response to fenfluramine is decreased in individuals with a past history of SB. ${ }^{62,63}$ In addition, activity in these brain regions was associated with intent and lethality of a previous suicidal act. ${ }^{61}$ See Jollant et al. ${ }^{64}$ for a more complete review of neuroimaging findings.

Previous studies in other populations combining neuroimaging and genetics suggest that the brain regions involved in vulnerability to SB are modulated by genetic polymorphisms previously associated with SB. For instance, the 5HTTLPR variant known to regulate expression of the $5 \mathrm{HT}$ transporter was found to modulate activation of the medial prefrontal cortex and amygdala during the resting state, ${ }^{65}$ and the amygdala or amygdala-prefrontal coupling during aversive stimulation. ${ }^{66,67}$

The findings described above suggest that neuropsychological, neurophysiological and neuroimaging alterations may represent valuable endophenotypes in SB (Figure 1), but with the exception of impulsive aggression do not currently meet stringent endophenotype criteria including heritability, state independence and familiar aggregation both in affected and unaffected relatives. Altered cognitive and emotional processes, modulated by specific genetic polymorphisms, were found in patients, even in the euthymic phase. These alterations may decrease the ability of some individuals to respond with resilience to life stressors or facilitate acting on emerging suicidal ideas. A number of other potential endophenotypes for SB exist as well, including hypothalamic-pituitary-adrenal axis hyperfunction. ${ }^{10,68}$

\section{Future directions, including animal model approaches to study the neurobiology of SB}

Future areas of research should include the simultaneous assessment of cognitive and emotional functions, neural activation and genetic polymorphisms, structural and functional connectivity, and pharmacological studies with different ligands. The biological differences between men and women vis-à-vis SB should be investigated, as well as the effects of age (adolescents, adults and elderly). Moreover, a practical model should be developed that includes a correlation between cognitive and neuroanatomical dysfunctions and the various steps of the suicidal process comprising psychological pain, suicidal ideation and the suicidal acts themselves. $^{64,69}$

A major advantage of the endophenotype approach is that the neurobiology underlying SB may be translated successfully from humans to other species. ${ }^{68}$ Animal models or tests are designed to reproduce some aspect of the disease, rather than the disease itself, thereby excluding dubious anthropomorphizing. Thus, although SB per se will never be modeled in non-human animals, it may be possible to reproduce some aspects of the underlying neurobiology. Approaches used to validate animal models or tests can be grouped into three categories: face validity (do animals behave similar to humans who have the illness), construct validity (do processes that result in human pathology also result in the abnormal animal behavior) and predictive validity (is the model responsive to effective medications). ${ }^{70-72} \mathrm{~A}$ successful example can be taken from schizophrenia research. Modeling endophenotypes such as impaired prepulse inhibition and impaired working memory in rodents has been successful in schizophrenia research, in regards to understanding the neurobiology underlying the disease, assessing the function of risk alleles, and in developing novel therapeutic approaches. However, just as it is not possible for rodents to be 'psychotic', it is not possible for a mouse to be 'suicidal'.

Indeed, it is not possible to develop animal models with face validity to human suicide. However, construct-valid approaches including those reliant on neurobiology, genetics and in particular endophenotypes, such as those discussed in this review, can be used. ${ }^{28,73,74}$ Some examples would be the behavior of mice in tests that assess their decision-making process, or levels of impulsive aggressive behavior, for example, a rodent version of the lowa gambling task exists where the profile in choice behavior retains many of the key characteristics of the human task. ${ }^{75,76}$ Serotonin transporter levels have been shown to modulate long-term decision making in this task in the rat (as it has been previously shown in humans) ${ }^{77}$ and lowa gambling task impairment has been associated with a decrease in 5-HIAA levels in the orbitofrontal cortex in a rat chronic pain model. ${ }^{78}$ The proposed link between this main metabolite of serotonin, orbitofrontal cortex function and decision making is significant, as deficiencies in these three parameters are implicated in suicide vulnerability. 
Drugs with recognized antisuicidal or prosuicidal effects provide a mechanism to assess the predictive validity of a potential model. In this regard, extensive evidence indicates that lithium is effective in the prevention of suicide in patients with mood disorders. ${ }^{28,79-81}$ Administration of lithium, compared with drugs equally effective at stabilizing mood, but less effective at reducing the risk of suicide such as valproate ${ }^{79,82}$ can be used to provide predictive validity of promising models. Interestingly, lithium was found to modify activation of the orbitofrontal cortex in pathological gamblers. ${ }^{83}$ The endophenotypic approach may be useful for the identification of potential mechanisms underlying the antisuicidal effect of lithium. ${ }^{28,84}$

\section{Relevance and limits of the endophenotypic approach}

There have been many discussions about the most appropriate criteria for evaluating the validity of potential endophenotypic markers; some of these criteria are widely accepted, whereas others are more controversial. ${ }^{17,85,86}$ Other terms such as 'intermediate phenotype' or 'biological marker' are sometimes used interchangeably, whereas they differ in their meanings; endophenotypes include the idea that a heritable quantitative phenotype is closer in the chain of causality to the genes underlying the disease, but the latter terms do not necessarily reflect genetic underpinnings, and a minority of biological markers meet more than one or two endophenotype criteria. $^{68,87}$ Such criteria are important as they protect against the too casual use of non-valid endophenotypes, which would lead to invalid genetic studies and disappointments in psychiatric research. $^{87}$

In a recent heuristic, paper Flint and Munafo ${ }^{85}$ performed several meta-analyses aimed at examining the basic assumption that effect sizes of genetic loci contributing to endophenotypes are larger than those contributing to disease susceptibility. By investigating several neuropsychological measures, catechol-O-methyl transferase (COMT) genotypes and schizophrenia, the authors concluded that the genetic basis for potential (cognitive) endophenotypes might be as genetically complex as the related psychiatric disease. This idea is close to the concept of fractality or scale invariance, in which the shapes remain complex irrespective of the scale. ${ }^{88}$ However, faced with psychiatric disorders, including SB, characterized by a high level of complexity, the endophenotypic strategy currently represents a valuable approach to enhance our understanding of the link between genes and neurobiological processes. This may ultimately provide trait markers of susceptibility to disease, models of the disease process, improvements in classification and diagnosis, elucidation of new therapeutic targets, and improvements in the development of animal disease models. However, although it was an original aim of this strategy, the endophenotype approach may not be most appropriate to robustly enhance our ability to discover new genetic polymorphisms related to disease. In other words, using endophenotypes to link the different levels of understanding (from genes to behavior through biochemistry and cognition) may be more useful than using endophenotypes to make de novo discoveries of new susceptibility genes.

\section{Conclusions}

Leading candidate endophenotypes for SB include impulsive/ aggressive personality traits, neuropsychological and neurophysiological responses, and functional changes in circuit activity as observed by brain imaging. Among these, only impulsive/aggressive personality traits meet all stringent endophenotype criteria. It is critical that future research efforts define the extent to which findings beyond impulsivity and aggression meet stringent endophenotype criteria including heritability, state independence and familial aggregation both in affected and unaffected relatives. Such putative endophenotypes may represent new and innovative outcomes that can be targeted to reduce the risk of $\mathrm{SB}$, and future research efforts should be directed to defining the degree to which such traits are specific for SB and genetic in origin. Endophenotypes should help us to discover the pathophysiology-related mechanisms involved in SB, and lead to the identification of potential new biological systems as therapeutic targets.

Considering endophenotypes, tested first in animals and then in humans, as potential targets for new treatments may enable us to circumvent the obstacles in pharmacological studies, represented by ethical concerns as well as issues with obtaining adequate sample sizes. Clinical trials could potentially aim to investigate the effects of a new compound, not on the rare SB directly, but on the related endophenotypes, measurable quantitatively, which would address the validity of assessing outcomes with low base rates in the general population, potentially avoiding false positives. This is now the case with the MATRICS and related programs aimed at cognition in schizophrenia. ${ }^{89}$ Moreover, measuring the same endophenotypes in unaffected relatives of cases will enhance the statistical power of such studies. Evaluation of new treatments for SB could be based on the involvement of identified cognitive and emotional processes, related to dysfunction of the orbitofrontal cortex in the pathophysiology of SB. Improving decision making and emotions, that is to say focused psychotherapeutic interventions, can be proposed to complement additional strategies. For example, it has been demonstrated that stimulation of the prefrontal cortex (ventromedial or dorsolateral) using repetitive transcranial magnetic stimulation in healthy volunteers may induce alterations in decision making and in the generation of emotional signals. ${ }^{90-92}$ Such findings may be translatable into therapeutic studies in SB, as has been carried out for craving in patients with addictions. ${ }^{93-95}$

We also conclude that it is possible to use animal models to study crucial aspects of the neurobiology underlying SB. Though SB cannot be reproduced in animals, suicide endophenotypes, risk alleles and neurochemical findings may be successfully translated from humans to other species. Emerging neuroscience data provide a better understanding of the factors leading to SB, independently of co-occurring psychopathology labeled in the diagnostic manuals. Additional neuropsychological and brain imaging studies, linked to genetic and environmental factors, are necessary to better understand vulnerability to SB, to identify vulnerable patients and to develop more specific therapeutic tools. 


\section{Conflict of interest}

The authors declare no conflict of interest.

Acknowledgements. This work was support by the American Foundation for Suicide Prevention (standard research grant to TDG), National Institute of Mental Health (R01 MH091816-01 to TDG), and the Gralnick Prize from the American Psychological Foundation and the NARSAD Lieber Prize for Outstanding Schizophrenia Research (to IIG).

1. Kessler RC, Berglund P, Borges G, Nock M, Wang PS. Trends in suicide ideation, plans, gestures, and attempts in the United States, 1990-1992 to 2001-2003. JAMA 2005; 293: 2487-2495.

2. Meyer RE, Salzman C, Youngstrom EA, Clayton PJ, Goodwin FK, Mann JJ et al. Suicidality and risk of suicide-definition, drug safety concerns, and a necessary target for drug development: a consensus statement. J Clin Psychiatry 2010; 71: e1-e21.

3. Linehan MM. Suicidal people. One population or two? Ann NY Acad Sci 1986; 487: 16-33.

4. Cheng AT, Chen TH, Chen CC, Jenkins R. Psychosocial and psychiatric risk factors for suicide. Case-control psychological autopsy study. Br J Psychiatry 2000; 177: 360-365.

5. Roy A, Rylander G, Sarchiapone M. Genetics of suicides. Family studies and molecular genetics. Ann NY Acad Sci 1997; 836: 135-157.

6. Brent DA, Bridge J, Johnson BA, Connolly J. Suicidal behavior runs in families. A controlled family study of adolescent suicide victims. Arch Gen Psychiatry 1996; 53: 1145-1152.

7. Mann JJ. Neurobiology of suicidal behaviour. Nat Rev Neurosci 2003; 4: 819-828.

8. Mann JJ. Psychobiologic predictors of suicide. J Clin Psychiatry 1987; 48(Suppl): 39-43.

9. Labonte B, Turecki $\mathrm{G}$. The epigenetics of suicide: explaining the biological effects of early life environmental adversity. Arch Suicide Res 2010; 14: 291-310.

10. Mann JJ, Currier DM. Stress, genetics and epigenetic effects on the neurobiology of suicidal behavior and depression. Eur Psychiatry 2010; 25: 268-271.

11. Mann JJ, Brent DA, Arango V. The neurobiology and genetics of suicide and attempted suicide: a focus on the serotonergic system. Neuropsychopharmacology 2001; 24 467-477.

12. Baud $P$. Personality traits as intermediary phenotypes in suicidal behavior: genetic issues. Am J Med Genet 2005; 133: 34-42.

13. Brezo J, Paris J, Turecki G. Personality traits as correlates of suicidal ideation, suicide attempts, and suicide completions: a systematic review. Acta Psychiatr Scand 2006; 113 180-206.

14. Mann JJ, Arango VA, Avenevoli S, Brent DA, Champagne FA, Clayton P et al. Candidate endophenotypes for genetic studies of suicidal behavior. Biol Psychiatry 2009; 65 556-563.

15. Courtet P, Guillaume S, Malafosse A, Jollant F. Genes, suicide and decisions. Eur Psychiatry 2010; 25: 294-296.

16. Gottesman II, Shields J. Schizophrenia and Genetics; A Twin Study Vantage Point. Academic Press Inc.: New York, 1972.

17. Gottesman II, Gould TD. The endophenotype concept in psychiatry: etymology and strategic intentions. Am J Psychiatry 2003; 160: 636-645.

18. Kendler KS, Neale MC. Endophenotype: a conceptual analysis. Mol Psychiatry 2010; 15 789-797.

19. Siever LJ. Endophenotypes in the personality disorders. Dialogues Clin Neurosci 2005; 7: 139-151.

20. Insel TR, Cuthbert BN. Endophenotypes: bridging genomic complexity and disorder heterogeneity. Biol Psychiatry 2009; 66: 988-989.

21. Leboyer M, Slama F, Siever L, Bellivier F. Suicidal disorders: a nosological entity per se? Am J Med Genet 2005; 133C: 3-7.

22. Rosen A. Detection of suicidal patients: an example of some limitations in the prediction of infrequent events. J Consult Psychol 1954; 18: 397-403.

23. Meehl PE, Rosen A. Antecedent probability and the efficiency of psychometric signs, patterns, or cutting scores. Psychol Bull 1955; 52: 194-216.

24. Roy A, Segal NL, Centerwall BS, Robinette CD. Suicide in twins. Arch Gen Psychiatry 1991; 48: 29-32.

25. Brent DA, Melhem N. Familial transmission of suicidal behavior. Psychiatr Clin North Am 2008; 31: 157-177.

26. Wasserman D, Terenius L, Wasserman J, Sokolowski M. The 2009 Nobel conference on the role of genetics in promoting suicide prevention and the mental health of the population. Mol Psychiatry 2010; 15: 12-17.

27. Jollant $F$, Lawrence NL, Olie E, Guillaume $S$, Courtet $P$. The suicidal mind and brain: a review of neuropsychological and neuroimaging studies. World $J$ Biol Pschiatry 2011; (e-pub ahead of print).

28. Kovacsics CE, Gottesman II, Gould TD. Lithium's antisuicidal efficacy: elucidation of neurobiological targets using endophenotype strategies. Ann Rev Pharmacol Toxicol 2009; 49: 175-198.

29. Grunebaum MF, Ramsay SR, Galfalvy HC, Ellis SP, Burke AK, Sher L et al. Correlates of suicide attempt history in bipolar disorder: a stress-diathesis perspective. Bipolar Disord 2006; 8(5 Part 2): 551-557.
30. Oquendo MA, Galfalvy H, Russo S, Ellis SP, Grunebaum MF, Burke A et al. Prospective study of clinical predictors of suicidal acts after a major depressive episode in patients with major depressive disorder or bipolar disorder. Am J Psychiatry 2004; 161: 1433-1441.

31. Caspi A, Moffitt TE, Newman DL, Silva PA. Behavioral observations at age 3 years predict adult psychiatric disorders. Longitudinal evidence from a birth cohort. Arch Gen Psychiatry 1996; 53: 1033-1039.

32. Melhem NM, Brent DA, Ziegler M, lyengar S, Kolko D, Oquendo M et al. Familial pathways to early-onset suicidal behavior: familial and individual antecedents of suicidal behavior. Am J Psychiatry 2007; 164: 1364-1370.

33. Brent DA, Oquendo M, Birmaher B, Greenhill L, Kolko D, Stanley B et al. Peripubertal suicide attempts in offspring of suicide attempters with siblings concordant for suicidal behavior. Am J Psychiatry 2003; 160: 1486-1493.

34. Turecki G. Dissecting the suicide phenotype: the role of impulsive-aggressive behaviours. $J$ Psychiatry Neurosci 2005; 30: 398-408.

35. Vaidyanathan U, Patrick CJ, Cuthbert BN. Linking dimensional models of internalizing psychopathology to neurobiological systems: affect-modulated startle as an indicator of fear and distress disorders and affiliated traits. Psychol Bull 2009; 135 909-942.

36. Bechara A, Damasio AR, Damasio H, Anderson SW. Insensitivity to future consequences following damage to human prefrontal cortex. Cognition 1994; 50: 7-15.

37. Jollant $F$, Bellivier F, Leboyer M, Astruc B, Torres S, Verdier R et al. Impaired decision making in suicide attempters. Am J Psychiatry 2005; 162: 304-310.

38. Jollant F, Lawrence NS, Olie E, O'Daly O, Malafosse A, Courtet $P$ et al. Decreased activation of lateral orbitofrontal cortex during risky choices under uncertainty is associated with disadvantageous decision-making and suicidal behavior. Neuroimage 2010; 51: 1275-1281.

39. Malloy-Diniz LF, Neves FS, Abrantes SS, Fuentes D, Correa H. Suicide behavior and neuropsychological assessment of type I bipolar patients. J Affect Disord 2009; 112: 231-236.

40. Martino DJ, Strejilevich SA, Torralva T, Manes F. Decision making in euthymic bipolar I and bipolar II disorders. Psychol Med 2010; 1-9.

41. Oldershaw A, Grima E, Jollant F, Richards C, Simic M, Taylor L et al. Decision making and problem solving in adolescents who deliberately self-harm. Psychol Med 2009; 39: 95-104.

42. Dombrovski AY, Clark L, Siegle GJ, Butters MA, Ichikawa N, Sahakian BJ et al. Reward/punishment reversal learning in older suicide attempters. Am J Psychiatry 2010; 167: 699-707.

43. Lovallo WR, Yechiam E, Sorocco KH, Vincent AS, Collins FL. Working memory and decision-making biases in young adults with a family history of alcoholism: studies from the Oklahoma family health patterns project. Alcohol Clin Exp Res 2006; 30: 763-773.

44. Jollant $F$, Buresi $C$, Guillaume $S$, Jaussent I, Bellivier $F$, Leboyer $M$ et al. The influence of four serotonin-related genes on decision-making in suicide attempters. Am J Med Genet $B$ Neuropsychiatr Genet 2007; 144B: 615-624.

45. da Rocha FF, Malloy-Diniz L, Lage NV, Romano-Silva MA, de Marco LA, Correa H. Decision-making impairment is related to serotonin transporter promoter polymorphism in a sample of patients with obsessive-compulsive disorder. Behav Brain Res 2008; 195: $159-163$.

46. Stoltenberg SF, Vandever JM. Gender moderates the association between 5-HTTLPR and decision-making under ambiguity but not under risk. Neuropharmacology 2010; 58 : 423-428.

47. Thorell LH. Valid electrodermal hyporeactivity for depressive suicidal propensity offers links to cognitive theory. Acta Psychiatr Scand 2009; 119: 338-349.

48. Critchley HD, Elliott R, Mathias CJ, Dolan RJ. Neural activity relating to generation and representation of galvanic skin conductance responses: a functional magnetic resonance imaging study. J Neurosci 2000; 20: 3033-3040.

49. Lykken DT, lacono WG, Haroian K, McGue M, Bouchard Jr TJ. Habituation of the skin conductance response to strong stimuli: a twin study. Psychophysiology 1988; 25: 4-15.

50. Storrie MC, Doerr HO, Johnson MH. Skin conductance characteristics of depressed subjects before and after therapeutic intervention. J Nerv Ment Dis 1981; 169: 176-179.

51. Guillaume S, Jollant F, Jaussent I, Lawrence N, Malafosse A, Courtet P. Somatic markers and explicit knowledge are both involved in decision-making. Neuropsychologia 2009; 47: 2120-2124.

52. Mann JJ, Huang YY, Underwood MD, Kassir SA, Oppenheim S, Kelly TM et al. A serotonin transporter gene promoter polymorphism (5-HTTLPR) and prefrontal cortical binding in major depression and suicide. Arch Gen Psychiatry 2000; 57: 729-738.

53. Monkul ES, Hatch JP, Nicoletti MA, Spence S, Brambilla P, Lacerda AL et al. Fronto-limbic brain structures in suicidal and non-suicidal female patients with major depressive disorder. Mol Psychiatry 2007; 12: 360-366.

54. Aguilar EJ, Garcia-Marti G, Marti-Bonmati L, Lull JJ, Moratal D, Escarti MJ et al. Left orbitofrontal and superior temporal gyrus structural changes associated to suicidal behavior in patients with schizophrenia. Prog Neuropsychopharmacol Biol Psychiatry 2008; 32: 1673-1676.

55. Wagner G, Koch K, Schachtzabel C, Schultz CC, Sauer H, Schlosser RG. Structural brain alterations in patients with major depressive disorder and high risk for suicide: evidence for a distinct neurobiological entity? Neuroimage 2011; 54: 1607-1614. 
56. van Heeringen $\mathrm{C}$, Audenaert $\mathrm{K}$, Van Laere $\mathrm{K}$, Dumont $\mathrm{F}$, Slegers $\mathrm{G}$, Mertens $\mathrm{J}$ et al. Prefrontal 5-HT2a receptor binding index, hopelessness and personality characteristics in attempted suicide. J Affect Dis 2003; 74: 149-158.

57. Cannon DM, Ichise M, Fromm SJ, Nugent AC, Rollis D, Gandhi SK et al. Serotonin transporter binding in bipolar disorder assessed using [11C]DASB and positron emission tomography. Biol Psychiatry 2006; 60: 207-217.

58. Leyton M, Okazawa H, Diksic M, Paris J, Rosa P, Mzengeza S et al. Brain regional alpha[11C]methyl-L-tryptophan trapping in impulsive subjects with borderline personality disorder. Am J Psychiatry 2001; 158: 775-782.

59. Jollant F, Lawrence NS, Giampietro V, Brammer MJ, Fullana MA, Drapier D et al. Orbitofrontal cortex response to angry faces in men with histories of suicide attempts. Am J Psychiatry 2008; 165: 740-748.

60. Jollant F, Lawrence NS, Olie E, O'Daly O, Malafosse A, Courtet P et al. Decreased activation of lateral orbitofrontal cortex during risky choices under uncertainty is associated with disadvantageous decision-making and suicidal behavior. Neuroimage 2010; 51: 1275-1281

61. Oquendo MA, Placidi GP, Malone KM, Campbell C, Keilp J, Brodsky B et al. Positron emission tomography of regional brain metabolic responses to a serotonergic challenge and lethality of suicide attempts in major depression. Arch Gen Psychiatry 2003; 60: 14-22

62. Correa H, Duval F, Mokrani M, Bailey P, Tremeau F, Staner L et al. Prolactin response to D-fenfluramine and suicidal behavior in depressed patients. Psychiatry Res 2000; 93 : 189-199.

63. Malone KM, Corbitt EM, Li S, Mann JJ. Prolactin response to fenfluramine and suicide attempt lethality in major depression. Br J Psychiatry 1996; 168: 324-329.

64. Jollant F, Lawrence NL, Olie E, Guillaume S, Courtet P. The suicidal mind and brain: review of neuropsychological and neuroimaging studies. World J Biol Psychiatry 2011; (in press).

65. Rao H, Gillihan SJ, Wang J, Korczykowski M, Sankoorikal GM, Kaercher KA et al. Genetic variation in serotonin transporter alters resting brain function in healthy individuals. Biol Psychiatry 2007; 62: 600-606.

66. Hariri AR, Tessitore A, Mattay VS, Fera F, Weinberger DR. The amygdala response to emotional stimuli: a comparison of faces and scenes. Neuroimage 2002; 17: 317-323.

67. Heinz A, Braus DF, Smolka MN, Wrase J, Puls I, Hermann D et al. Amygdala-prefronta coupling depends on a genetic variation of the serotonin transporter. Nat Neurosci 2005; 8 : 20-21.

68. Gould TD, Gottesman II. Psychiatric endophenotypes and the development of valid animal models. Genes Brain Behav 2006; 5: 113-119.

69. Olie E, Guillaume $S$, Jaussent I, Courtet $P$, Jollant F. Higher psychological pain during a major depressive episode may be a factor of vulnerability to suicidal ideation and act. $J$ Affect Disord 2010; 120: 226-230.

70. Geyer MA, Markou A. Animal models of psychiatric disorders. In: Bloom FE, Kupfer DJ (eds). Psychopharmacology: the Fourth Generation of Progress. Raven Press: New York, 1995, pp 787-798.

71. Willner P. The validity of animal models of depression. Psychopharmacology (Berl) 1984; 83: $1-16$.

72. McKinney WT. Animal models of depression: an overview. Psychiatr Dev 1984; 2: 77-96

73. Preti A. Animal model and neurobiology of suicide. Prog Neuropsychopharmacol Bio Psychiatry 2011; (e-pub ahead of print).

74. Malkesman O, Pine DS, Tragon T, Austin DR, Henter ID, Chen G et al. Animal models of suicide-trait-related behaviors. Trends Pharmacol Sci 2009; 30: 165-173.

75. van den Bos R, Lasthuis W, den Heijer E, van der Harst J, Spruijt B. Toward a rodent model of the lowa gambling task. Behav Res Methods 2006; 38: 470-478.

76. Rivalan M, Ahmed SH, Dellu-Hagedorn F. Risk-prone individuals prefer the wrong options on a rat version of the lowa Gambling Task. Biol Psychiatry 2009; 66: 743-749.

77. Homberg JR, van den Bos R, den Heijer E, Suer R, Cuppen E. Serotonin transporter dosage modulates long-term decision-making in rat and human. Neuropharmacology 2008; 55: 80-84.

78. Pais-Vieira M, Mendes-Pinto MM, Lima D, Galhardo V. Cognitive impairment of prefrontaldependent decision-making in rats after the onset of chronic pain. Neuroscience 2009; 161 : $671-679$.
79. Goodwin FK, Fireman B, Simon GE, Hunkeler EM, Lee J, Revicki D. Suicide risk in bipolar disorder during treatment with lithium and divalproex. JAMA 2003; 290: 1467-1473.

80. Baldessarini RJ, Tondo L, Davis P, Pompili M, Goodwin FK, Hennen J. Decreased risk of suicides and attempts during long-term lithium treatment: a meta-analytic review. Bipolar Disord 2006; 8(5 Part 2): 625-639.

81. Muller-Oerlinghausen B. Arguments for the specificity of the antisuicidal effect of lithium. Eur Arch Psychiatry Clin Neurosci 2001; 251(Suppl 2): II72-II75.

82. Collins JC, McFarland BH. Divalproex, lithium and suicide among Medicaid patients with bipolar disorder. J Affect Disord 2007; 107: 23-28.

83. Hollander E, Buchsbaum MS, Haznedar MM, Berenguer J, Berlin HA, Chaplin W et al. FDG-PET study in pathological gamblers. 1. Lithium increases orbitofrontal, dorsolateral and cingulate metabolism. Neuropsychobiology 2008; 58: 37-47.

84. Kovacsics CE, Gould TD. Shock-induced aggression in mice is modified by lithium. Pharmacol Biochem Behav 2010; 94: 380-386.

85. Flint J, Munafo MR. The endophenotype concept in psychiatric genetics. Psychol Med 2007; 37: 163-180.

86. Cannon TD, Keller MC. Endophenotypes in the genetic analyses of mental disorders. Annu Rev Clin Psychol 2006; 2: 267-290.

87. Walters JT, Owen MJ. Endophenotypes in psychiatric genetics. Mol Psychiatry 2007; 12: 886-890.

88. Bullmore E, Barnes A, Bassett DS, Fornito A, Kitzbichler M, Meunier D et al. Generic aspects of complexity in brain imaging data and other biological systems. Neuroimage 2009; 47: 1125-1134.

89. Barnett JH, Robbins TW, Leeson VC, Sahakian BJ, Joyce EM, Blackwell AD. Assessing cognitive function in clinical trials of schizophrenia. Neurosci Biobehav Rev 2010; 34: $1161-1177$

90. Knoch D, Gianotti LR, Pascual-Leone A, Treyer V, Regard M, Hohmann M et al. Disruption of right prefrontal cortex by low-frequency repetitive transcranial magnetic stimulation induces risk-taking behavior. J Neurosci 2006; 26: 6469-6472.

91. Schutter DJ, van Honk J. Increased positive emotional memory after repetitive transcranial magnetic stimulation over the orbitofrontal cortex. J Psychiatry Neurosci 2006; 31: 101-104.

92. van Honk J, Schutter DJ, d'Alfonso A, Kessels RP, Postma A, de Haan EH. Repetitive transcranial magnetic stimulation at the frontopolar cortex reduces skin conductance but not heart rate: reduced gray matter excitability in orbitofrontal regions. Arch Gen Psychiatry 2001; 58: 973-974.

93. Eichhammer $\mathrm{P}$, Johann M, Kharraz A, Binder H, Pittrow D, Wodarz $\mathrm{N}$ et al. High-frequency repetitive transcranial magnetic stimulation decreases cigarette smoking. J Clin Psychiatry 2003; 64: 951-953

94. Mishra BR, Nizamie SH, Das B, Praharaj SK. Efficacy of repetitive transcranial magnetic stimulation in alcohol dependence: a sham-controlled study. Addiction 2010; 105: 49-55.

95. Camprodon JA, Martinez-Raga J, Alonso-Alonso M, Shih MC, Pascual-Leone A. One session of high frequency repetitive transcranial magnetic stimulation (rTMS) to the right prefrontal cortex transiently reduces cocaine craving. Drug Alcohol Depend 2007; 86: 91-94.

96. Currier D, Mann JJ. Stress, genes and the biology of suicidal behavior. Psychiatr Clin North Am 2008; 31: 247-269.

97. Bondy B, Buettner A, Zill P. Genetics of suicide. Mol Psychiatry 2006; 11: 336-351.

98. Brezo J, Klempan T, Turecki G. The genetics of suicide: a critical review of molecular studies. Psychiatr Clin North Am 2008; 31: 179-203.

Translational Psychiatry is an open-access journal published by Nature Publishing Group. This work is licensed under the Creative Commons Attribution-NoncommercialNo Derivative Works 3.0 Unported License. To view a copy of this license, visit http://creativecommons.org/licenses/by-nc-nd/3.0/ 